\title{
High-latitude plasma convection from Cluster EDI measurements: method and IMF-dependence
}

\author{
S. E. Haaland ${ }^{1, *}$, G. Paschmann ${ }^{1}$, M. Förster ${ }^{2}$, J. M. Quinn ${ }^{3,{ }^{* *}}$, R. B. Torbert $^{3}$, C. E. McIlwain ${ }^{4}$, H. Vaith ${ }^{1}$, \\ P. A. Puhl-Quinn ${ }^{3}$, and C. A. Kletzing ${ }^{5}$ \\ ${ }^{1}$ Max-Planck-Institut für extraterrestrische Physik, Garching, Germany \\ ${ }^{2}$ GeoForschungsZentrum Potsdam, Potsdam, Germany \\ ${ }^{3}$ University of New Hampshire, Durham, NH 03824, USA \\ ${ }^{4}$ University of California at San Diego, La Jolla, CA 94304, USA \\ ${ }^{5}$ University of Iowa, Iowa City, IA 52242, USA \\ *also at: Department of Physics, University of Bergen, Norway \\ ** now at: Boston University, Boston, MA 02215, USA
}

Received: 29 September 2006 - Revised: 9 January 2007 - Accepted: 22 January 2007 - Published: 1 February 2007

\begin{abstract}
We have used vector measurements of the electron drift velocity made by the Electron Drift Instrument (EDI) on Cluster between February 2001 and March 2006 to derive statistical maps of the high-latitude plasma convection. The EDI measurements, obtained at geocentric distances between $\sim 4$ and $\sim 20 R_{E}$ over both hemispheres, are mapped into the polar ionosphere, and sorted according to the clock-angle of the interplanetary magnetic field (IMF), measured at ACE and propagated to Earth, using best estimates of the orientation of the IMF variations. Only intervals of stable IMF are used, based on the magnitude of a "bias-vector" constructed from 30-min averages. The resulting data set consists of a total of $5862 \mathrm{~h}$ of EDI data. Contour maps of the electric potential in the polar ionosphere are subsequently derived from the mapped and averaged ionospheric drift vectors. Comparison with published statistical results based on Super Dual Auroral Radar Network (SuperDARN) radar and low-altitude satellite measurements shows excellent agreement between the average convection patterns, and in particular the lack of mirror-symmetry between the effects of positive and negative IMF $B_{y}$, the appearance of a duskward flow component for strongly southward IMF, and the general weakening of the average flows and potentials for northerly IMF directions. This agreement lends credence to the validity of the assumption underlying the mapping of the EDI data, namely that magnetic field lines are equipotentials. For strongly northward IMF the mapped EDI data show the clear emergence of two counter-rotating lobe cells with a channel of sunward flow between them. The total potential drops across the polar caps obtained from the mapped EDI data are intermediate between the radar and the low-altitude satellite results.
\end{abstract}

Correspondence to: S. E. Haaland

(stein.haaland@mpe.mpg.de)
Keywords. Ionosphere (Plasma convection) - Magnetospheric physics (Electric fields; Magnetospheric configuration and dynamics)

\section{Introduction}

Solar wind-magnetosphere interaction leads to a large-scale internal convection of magnetospheric plasma and magnetic flux that extends all the way down to the ionosphere. The reconnection hypothesis of Dungey (1961) explains the dependence of the basic convection pattern on the orientation of the interplanetary magnetic field (IMF) carried by the solar wind. For southward IMF, reconnection occurs on the dayside magnetopause with closed magnetospheric field lines. Once interconnected, open magnetic flux tubes are carried by the solar wind over the poles downstream, penetrating deeper and deeper into the magnetotail, where they eventually reconnect again to form closed field lines that are convected sunward past the Earth. In the high-latitude ionosphere the result is the familiar two-cell pattern, with anti-sunward flow over the polar caps returning to the dayside via the dawn and dusk flanks. A small fraction of the anti-sunward flow may occur on closed magnetic field lines as a result of quasiviscous interaction at the magnetopause (Axford and Hines, 1961). The potential difference - the polar cap potential may be more than $100 \mathrm{kV}$ during periods of strongly southward IMF. The twin-cell flow exhibits a number of dawndusk asymmetries that are oppositely directed in the Northern and Southern Hemispheres and whose sense depends on the IMF $B_{y}$ component. This effect can be understood (e.g., Cowley and Lockwood, 1992) in terms of the tension exerted on newly reconnected field lines in the presence of an IMF

Published by Copernicus GmbH on behalf of the European Geosciences Union. 
$B_{y}$, as observed in situ by Gosling et al. (1990). This leads to asymmetrical additions of open magnetic flux tubes to the tail lobes. For northward IMF, reconnection moves from the dayside to the region tailward of the cusps, where interplanetary field lines now reconnect with polar cap field lines that were already open (Dungey, 1963; Russell, 1972). The result is a three- or four-cell pattern depending on IMF $B_{y}$, with weak sunward convection over part of the polar cap. Discussions of the convection patterns as a function of the IMF are given, for example, in Cowley (1982); Reiff and Burch (1985); Cowley and Lockwood (1992); Lockwood and Moen (1999).

Most of our knowledge of polar cap convection comes from low-altitude satellite measurements and empirical models derived from them (e.g., Heppner, 1972; Heppner and Maynard, 1987; Rich and Hairston, 1994; Weimer, 1995; Papitashvili and Rich, 2002; Weimer, 2005), and from groundbased observations with radars (e.g., Greenwald et al., 1995a; Ruohoniemi and Baker, 1998; Ruohoniemi and Greenwald, 2005) and magnetometers (e.g., Kamide et al., 1981; Richmond and Kamide, 1988). Measuring the state of plasma convection in the polar cap is challenging and the various techniques have different limitations and strengths. Lowaltitude satellite measurements of the drift velocity provide the most direct access, but only along the satellite's orbit. Full coverage of the polar cap therefore requires suitable orbits and the assembly of a data base using a large number of passes. In the case of radar based measurements, such as those from the Super Dual Auroral Radar Network (SuperDARN), the strengths include nearly instantaneous spatial coverage, while on the other hand the measurements can be limited by the absence of a backscattered signal, the restriction to line-of-sight measurements, and limited coverage near the poles and in the Southern Hemisphere. Estimation of the ionospheric electric field from ground based magnetometers requires knowledge of the ionospheric conductivity, which is not easy to obtain.

In this and an accompanying paper (Förster et al., 2007 ${ }^{1}$ ), we present results from a statistical study of high-latitude convection based on measurements by the Electron Drift Instrument (EDI) on Cluster. EDI directly measures the full two-dimensional drift velocity perpendicular to the magnetic field with high accuracy. The Cluster spacecraft, due to their $90^{\circ}$ inclination orbits, completely cover both polar caps twice per year. Cluster measurements are, however, obtained at large distances from the ionosphere. Any comparison with ionospheric convection maps thus requires mapping of the EDI measurements to ionospheric altitudes, which is valid procedure only if the magnetic field lines threading the Cluster location are equipotentials.

Results from EDI obtained during 20 polar cap passes under varying IMF conditions were already reported earlier

\footnotetext{
${ }^{1}$ Förster, M., Paschmann, G., Haaland, S., et al.: High-latitude plasma convection form Cluster EDI: variances and solar wind correlation, Ann. Geophys., in preparation, 2007.
}

(Vaith et al., 2004). Some preliminary statistical maps of polar ionospheric convection from a limited EDI dataset were presented in Förster et al. (2006). For a limited time period (July through October 2001), EDI convection measurements in the tail lobe at distances between 5 and $15 R_{E}$ downtail were published by Noda et al. (2003). Complementary papers on the plasma convection measured by EDI in the inner magnetosphere have been published by Matsui et al. (2004, 2005).

In the present paper we first discuss the data selection and analysis methods, before presenting the results in terms of polar maps of the convection velocities and electric potentials, sorted according to the direction of the IMF as measured on the Advanced Composition Explorer (ACE). In the accompanying paper (Förster et al., 2007 ${ }^{1}$ ) we explore the effects of other sortings of the EDI data, and discuss the variability of the convection velocities.

\section{The data}

\subsection{Cluster EDI data}

Cluster is a European Space Agency (ESA) project comprising four identical satellites flying in close formation around the Earth. Cluster has a nearly $90^{\circ}$ inclination elliptical polar orbit, with perigee at around $4 R_{E}$ and apogee around $20 R_{E}$ geocentric distance, and an orbital period of approximately $57 \mathrm{~h}$. Details about the Cluster mission can be found in Escoubet et al. (1997).

Measurements of the plasma convection (or drift) velocity were obtained with the Electron Drift Instrument (EDI). The basis of the electron-drift technique is the injection of two weak beams of electrons and their detection after one or more gyrations in the ambient magnetic field. Because of their cycloidal motion, beam electrons can return to the associated detectors only when fired in directions uniquely determined by the magnitude and direction of the plasma drift velocity. Successful operation therefore requires continuous tracking of those directions. The drift velocity is computed either from the direction of the beams (via triangulation) or from the difference in their times-of-flight. The EDI technique, hardware, operation, and data analysis method have been described in detail in earlier publications (Paschmann et al., 1997, 2001; Quinn et al., 2001).

An important advantage of EDI for high-latitude convection measurements is its immunity from wake effects that can interfere with the double-probe measurements under conditions of low plasma density that often occur over the polar cap. Furthermore, EDI measures the entire vector drift velocity, which is equivalent to the transverse electric field when gradient drift effects are small, as is the case here. The E-field thus include any component along the spacecraft spin axis, while the Electric Field and Wave Experiment (EFW), which is based on the double-probe technique, measures the electric 
field only in the spin-plane. The suitability of EDI for polar cap convection measurements has been demonstrated in a recent publication (Eriksson et al., 2006) that compares EDI and EFW measurements for a number of different ambient conditions. The large magnetic fields encountered by Cluster over the polar caps also imply that the drift velocity was mostly obtained with the triangulation technique, which due to its purely geometrical nature is intrinsically very accurate.

EDI data have been processed down to 1-s resolution, but for the purpose of this paper we have used 1-min averages. The expansion of the flux tube diameters with altitude and the slow orbital motion at high altitude means that even 1-min resolution measurements translate into excellent spatial resolution when mapped into the ionosphere. Over the central polar cap the Cluster spacecraft speed is $3-4 \mathrm{~km} \mathrm{~s}^{-1}$. Measurements with 1-min cadence, taken at a position where the field is $100 \mathrm{nT}$, are only of order $10 \mathrm{~km}$ apart when mapped into the ionsophere.

EDI measurements are available for Cluster spacecraft 1 and 3 throughout the entire period discussed here, and until April 2004 for spacecraft 2. No EDI measurements are available from spacecraft 4 . Operational constraints limit the availability of EDI data. The EDI electron beams, which are amplitude-modulated to enable time-of-flight measurements, can interfere with the wave measurements on Cluster. EDI is therefore operated with a duty-cycle that has been negotiated with the other experiments on Cluster. These restrictions primarily affect regions of low magnetic fields.

\subsection{Solar wind and auxilliary data}

Interplanetary magnetic field (IMF) and solar wind plasma data are taken from the ACE magnetic field instrument MAG (Smith et al., 1998) at $16 \mathrm{~s}$ resolution and the solar wind instrument SWEPAM (McComas et al., 1998) at $64 \mathrm{~s}$ resolution. MAG and SWEPAM data are resampled to one minute time resolution, thereafter time shifted to represent the IMF conditions at the frontside magnetopause, as described below.

The T2001 magnetic field model (Tsyganenko, 2002a,b) that we use for mapping requires the $D_{s t}$ (Disturbed Storm Time) index as an input parameter. $D_{s t}$ is provided as hourly averages by the World Data Center A (WDCA), at Kyoto University, Japan. The $D_{s t}$ index has been resampled and interpolated to one minute timetags of the Cluster EDI data.

\subsection{Data coverage}

When dealing with statistics over a 5 year period, there inevitably are periods where one or more of the data sources suffer from data gaps. In addition to gaps in the EDI measurements, gaps also occur in the solar wind data. Other data we use, e.g., the $D_{s t}$ index, have nearly $100 \%$ coverage, and do not affect the overall coverage. We have dealt with data gaps in the following way:
Table 1. Data coverage in hours of observations for the present study.

\begin{tabular}{l|rrr|rrr}
\hline Year & Hours & Valid & Stable & \multicolumn{3}{|c}{ Mapped EDI vectors } \\
& & ACE & IMF & SC1 & SC2 & SC3 \\
\hline $2001^{2}$ & 8019 & 6845 & 4612 & 356 & 311 & 334 \\
2002 & 8760 & 7446 & 4632 & 440 & 291 & 686 \\
2003 & 8760 & 7875 & 3262 & 564 & 225 & 445 \\
2004 & 8784 & 7143 & 4176 & 547 & 15 & 514 \\
2005 & 8760 & 6479 & 4358 & 496 & - & 444 \\
$2006^{3}$ & 2159 & 1483 & 1072 & 89 & - & 104 \\
Total & 45242 & 37274 & 22114 & 2493 & 842 & 2527 \\
\hline
\end{tabular}

\footnotetext{
${ }^{1}$ Data from SC2 only until early April 2004.

2 Data for 2001 start in February.

${ }^{3}$ Data for January-March only.
}

Data gaps in the ACE measurements with duration shorter than $10 \mathrm{~min}$ are linearly interpolated. For gaps longer than $10 \mathrm{~min}$, the solar wind conditions required for mapping cannot be established with reasonable confidence, and no further processing of the EDI data is done. Since the solar wind history is an input parameter of the T2001 magnetic field model used to map the EDI data to ionospheric altitudes, some attention is still needed: The G1 and G2 factors of the T2001 model are based on the preceding $1 \mathrm{~h}$ history of the solar wind. If there is a gap within this period, the G1 and G2 factors are simply based on fewer samples. In the extreme case where the full preceding hour of data is missing, the G1 and G2 factors are both set to zero. This is legitimate since the G1 and G2 factors do not have a significant impact on the mapping for the regions covered by our study.

During the 62 months $(\simeq 45000 \mathrm{~h})$ we have included in our study, approximately $37000 \mathrm{~h}$ of ACE data were available after using the described interpolation scheme. Of these, slightly more than $22000 \mathrm{~h}$ satisfy our IMF stability criteria (see below). High-quality EDI data from Cluster SC1, SC2 and $\mathrm{SC} 3$ are available within the polar magnetosphere (at magnetic latitudes $\geq 58^{\circ}$ ) for a total of $5862 \mathrm{~h}$. The details are given in Table 1.

EDI measurements are taken from geocentric distances between $\sim 4$ and $\sim 20 R_{E}$. The upper panel of Fig. 1 shows the altitude distribution of the EDI data used in this study. The sharp drop in coverage beyond $8 R_{E}$ is due to the limited operation in weak magnetic fields noted earlier. The bottom plot in Fig. 1 shows the distribution of IMF clock angles.

\section{Method}

The processing chain runs as follows: First, the solar wind data from the ACE spacecraft is shifted to represent the conditions near Earth's dayside magnetopause. Auxiliary parameters such as dynamic pressure as well as the G1 and G2 

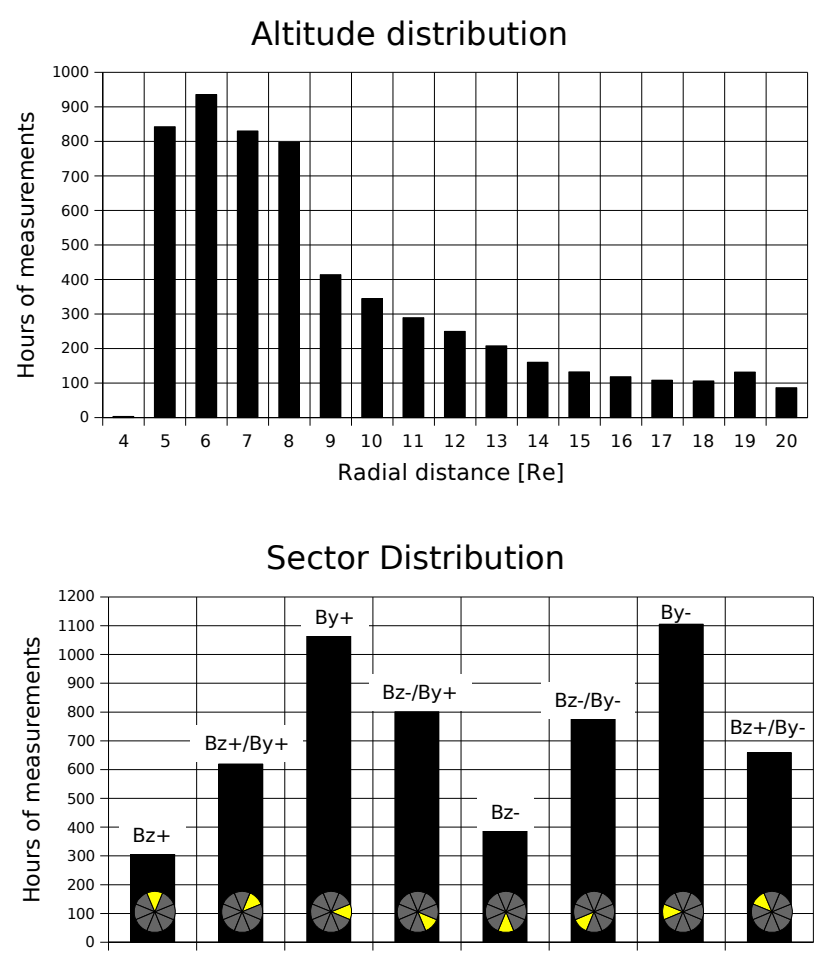

Fig. 1. Top panel: distribution of the EDI measurements versus geocentric radial distance. Most of the EDI measurements are taken at distances between 4 and $8 R_{E}$. The drop-off beyond $8 R_{E}$ is due to constraints on EDI operations to avoid interference with the wave experiment onboard Cluster. Bottom panel: distribution of the IMF clock-angle for the EDI measurements used in this study. The two peaks represent the average IMF directions along the Parker spiral.

parameters, needed for the mapping procedure, are also calculated. The output of this process is a data set with time shifted solar wind data. Next, the time shifted solar wind information is filtered to remove periods where the IMF conditions are considered too variable for establishing a welldefined magnetospheric response. This process creates a subset of the original solar wind data in which the IMF directions are reasonably stable within a $30 \mathrm{~min}$ period. Only about $50 \%$ of the solar wind data remain after this step. Finally, EDI convection measurements are mapped from the Cluster orbit into the ionosphere at $400 \mathrm{~km}$ altitude. In the next sections, we describe each of these steps in detail.

\subsection{Solar wind propagation}

Since the solar wind data used in our study is taken from the ACE spacecraft orbiting the L1 libration point, these measurements have to be time shifted to be representative for the condition at the subsolar magnetopause, assumed to be $10 R_{E}$ upstream of the Earth. The standard approach used by many researchers has been to compute this time delay simply as $x / V_{x}$, where $V_{x}$ and $x$ are the solar wind speed and

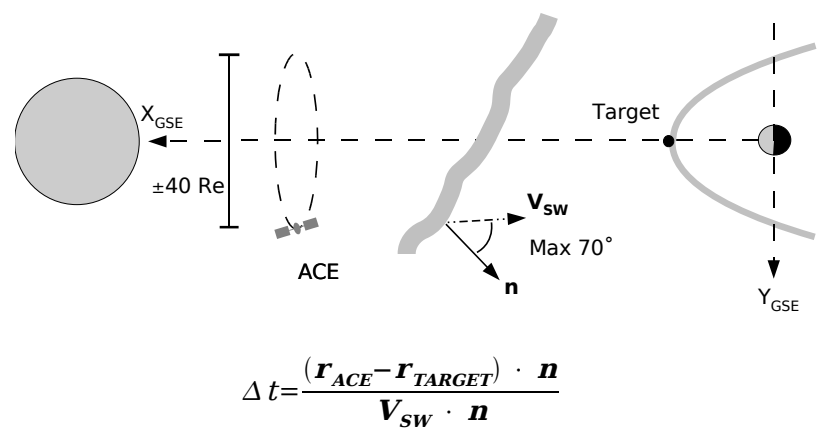

Fig. 2. Determination of solar wind propagation delay. The real position of the solar wind monitor, $\mathbf{r}_{\mathrm{ACE}}$, as well as the orientation of the phase front, $\mathbf{n}$, are taken into account.

difference in GSE x position of the solar wind monitor and the target (the upstream magnetopause), respectively.

A problem with this method is that the IMF variations appear to occur along surfaces, referred to as "phase fronts", that can be tilted at arbitrary angles with respect to the solar wind velocity. Figure 2 schematically illustrates the effect this can have on the propagation. According to this figure the tilt has no effect on the propagation delay as long as it is $90^{\circ}$ or the IMF monitor and the target are connected by a solar wind stream line. As the ACE orbit has large excursions (up to $\pm 40 R_{E}$ ) in GSE-y and up to $\pm 20 R_{E}$ in z, while the target is at $(\mathrm{y}, \mathrm{z})=0$, such alignment never occurs, and the effect from such tilts can therefore be quite large. This has been demonstrated by Weimer et al. (2002), using the ACE spacecraft and a few near-Earth satellites as "targets". In a subsequent paper, Weimer et al. (2003) calculated the orientation of the "phase fronts" from a running minimum variance analysis (MVAB) of the IMF and found that this gave propagation delays in reasonable agreement with observations at the target spacecraft. In our study, we have used a slightly corrected method (Haaland et al., 2006) that is based on a constrained MVAB, referred to as MVAB-0. Following Weimer et al. (2003), we first apply the variance analysis to an approximately 8-min interval. If the variance analysis fails, i.e., the ratio between the two non-zero eigenvalues is small, a longer time interval of approximately $24 \mathrm{~min}$ is chosen and the analysis repeated. If neither interval gives a reliable normal, the previous valid orientation is kept.

From the illustration in Fig. 2 it is apparent that phase front orientations that are almost aligned with the solar wind can give very large time delays. Weimer et al. (2003) required that the phase front normal should not deviate more than $70^{\circ}$ from the Sun-Earth line. If this limit was exceeded, the previous valid phase front normal was used. We replaced this condition by one where the $70^{\circ}$ limit was applied to the angle between the normal and the solar wind velocity, because the solar wind velocity can deviate substantially from the SunEarth line. Finally, for delay times exceeding $165 \mathrm{~min}$, the previous valid delay time is kept. 


\subsection{IMF stability}

Even with the above method to shift the IMF information, there will still be some uncertainties in the time delay calculation. It also takes some time before magnetospheric convection responds to changes in the external conditions. To be reasonably certain that the IMF conditions were stable enough, we defined a stability criterion, the principle of which is illustrated in Fig. 3. The top part shows, for the simple case of just three IMF vectors in the GSM-YZ plane, how the bias vector is constructed. Each vector is first normalized to 1 , thereafter, the vectors are added together, and finally divided by 3 to yield the average. The average vector is referred to as the "bias vector". The angle, $\theta$, between the bias vector and the GSM-Z axis defines the clock angle, and its magnitude is a measure of the stability of that clock angle. If the IMF direction were perfectly stable, i.e., the three $\mathbf{B}_{\mathbf{i}}$ vectors in the example were parallel, the bias vector, $\mathbf{b}$, would have unit length. Any variation in direction between the individual $\mathbf{B}_{\mathbf{i}}$ vectors leads to a bias vector length less than unity; the larger the spread, the smaller the length.

For this study, the bias vector was constructed by averaging over a time interval starting $20 \mathrm{~min}$ before and ending 10 min after the time of an EDI measurement. Since the time resolution used is $1 \mathrm{~min}$, the bias vector is thus based on 30 individual $\mathbf{B}_{\mathbf{i}}$ vectors. The asymmetric time interval takes into account any uncertainty in the solar wind propagation and an additional 10 min needed to set up the convection (e.g., Ridley et al., 1998).

With the chosen $30 \mathrm{~min}$ interval, a linear variation in the IMF clock angle of approximately $\pm 27^{\circ}$ gives a bias vector length 0.96. Time periods when the bias vector length is below this threshold are considered "unstable", and excluded from this study. The threshold of 0.96 may seem arbitrary, but was selected after some experimentation, and is a compromise that gives reasonable stability filtering, but still leaves enough data records for the statistics. With this threshold, the IMF is classified as "stable" about $50 \%$ of the time.

As an illustration, the bottom panel of Fig. 3 shows an example of IMF clock angle variations, and the corresponding bias vector length. Panel (a) shows the time shifted $1 \mathrm{~min}$ resolution IMF $B_{y}$ and $B_{z}$ components. Panel (b) shows the corresponding clock angle, smoothed by the averaging process. Panel (c) shows the bias vector length. The rapid IMF variations around 15:00-16:00 UT, and after 21:00 UT, lead to bias vector lengths below the 0.96 threshold, whereas the slow rotation between 16:00 and 21:00 does not cause the bias vector length to drop below the threshold.

When looking at the IMF dependence, we sort our results into 8 IMF clock-angle sectors, each $45^{\circ}$ wide, where the average IMF angle ( $\theta$ in the upper right of Fig. 3 ) defines the IMF clock angle.
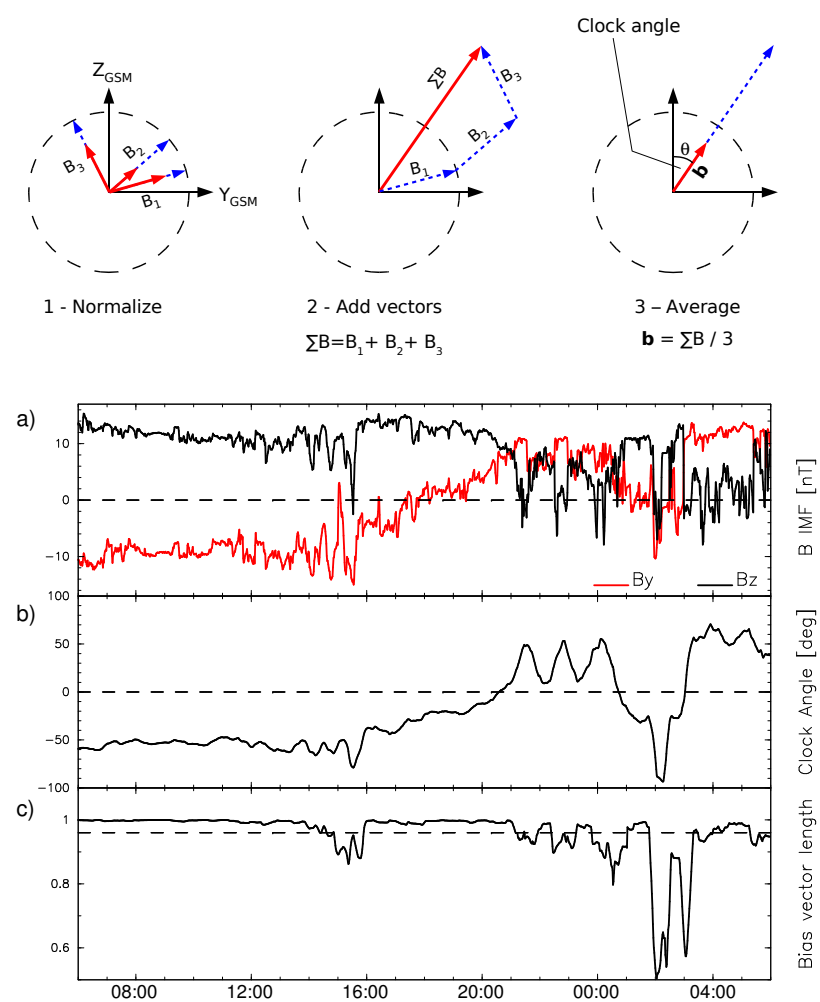

Fig. 3. Top: Illustration of the construction of the bias vector,b, used for IMF stability filtering. Bottom, panel (a): time shifted IMF $B_{y}$ (red) and $B_{z}$ (black) for 25 March, 2002; panel (b): the resulting clock angle; panel (c): the bias vector magnitude, on which we base out IMF stability filtering, using a threshold of 0.96 (dashed line).

\subsection{Mapping the EDI vectors}

Figure 4 shows the geometry of the mapping of the EDI measurements on Cluster into the ionosphere. Assuming a spacecraft position at $\mathbf{x}_{0}^{(m)}$, we first map this location along the magnetic field to $400 \mathrm{~km}$ altitude in the ionosphere, using the Tsyganenko T2001 model (including updates of the code, dated 24 June 2006), arriving at $\mathbf{x}_{0}^{(i)}$. We then do the same for a point $\mathbf{x}_{1}^{(m)}$ that is displaced from $\mathbf{x}_{0}^{(m)}$ by a vector distance $\mathbf{d}^{(m)}=d^{(m)} \widehat{\mathbf{V}}^{(m)}$, where $\widehat{\mathbf{V}}^{(m)}$ is a unit vector along the convection velocity, $\mathbf{V}^{(m)}$, measured at Cluster. This point maps to $\mathbf{x}_{1}^{(i)}$. Since the magnetic field converges, the separation, $\mathbf{d}^{(i)}$, is much smaller than $\mathbf{d}^{(m)}$. As field lines are assumed to be frozen into the flow, the velocity in the ionosphere, $\mathbf{V}^{(i)}$, follows from the relation $\mathbf{d}^{(i)} / \mathbf{d}^{(m)}=\mathbf{V}^{(i)} / \mathbf{V}^{(m)}$. The magnitude, $d^{(m)}$, of the distance between $\mathbf{x}_{0}^{(m)}$ and $\mathbf{x}_{1}^{(m)}$ (in $\mathrm{km}$ ), was chosen as $d^{(m)}=50 \sqrt{B^{(i)} / B^{(m)}}$. Since transverse distances at Cluster locations map to distances in the ionosphere roughly as $1 /\left(\sqrt{B^{(i)} / B^{(m)}}\right)$, this choice for $d^{(m)}$ assures that the mapped positions, $\mathbf{x}_{0}^{(i)}$ and $\mathbf{x}_{1}^{(i)}$, are separated by roughly $50 \mathrm{~km}$, or about a quarter of the bin width, regardless of the altitude at which the measurements were made. The choice 


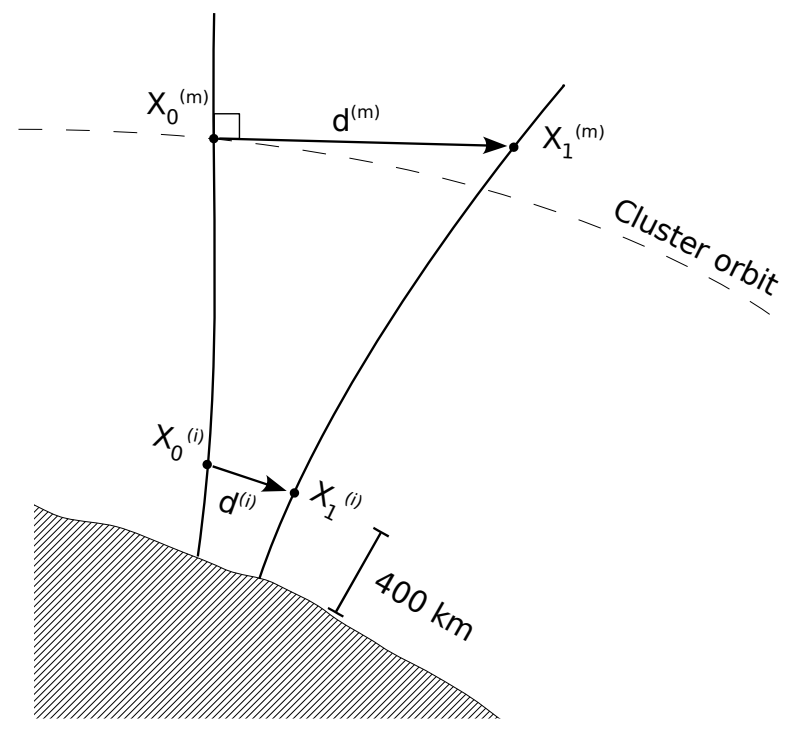

Fig. 4. Illustration of the mapping procedure. The measured convection velocity at location $\mathbf{x}_{0}^{(m)}$ is converted into a spatial vector $\mathbf{d}^{(m)}$ by multiplying with a scaling factor. The endpoints of this vector, $\mathbf{x}_{0}^{(m)}$ and $\mathbf{x}_{1}^{(m)}$ are then mapped into the ionosphere, based upon the Tsyganenko T2001 model, where the corresponding ionospheric convection velocity is then obtained from the mapped vector $\mathbf{d}^{(i)}$. The scales are exaggerated for clarity.

of $50 \mathrm{~km}$ was found to be a reasonable compromise between uncertainties and distortion in the mapping.

The mapped vectors are binned and averaged in 784 bins with $2^{\circ}$ width in latitude and variable longitudinal width such that the bin area is constant, $\simeq 5 \times 10^{4} \mathrm{~km}^{2}$, projected to the Earth's surface. Depending on the intended use, we use either Solar Magnetospheric (SM) or Altitude Adjusted Corrected Geomagnetic (AACGM) coordinates (e.g., Weimer, 2005, Appendix A). Mapped vectors with magnitude larger than $5 \mathrm{~km} \mathrm{~s}^{-1}$ are removed before averaging, because they can safely be considered as outliers. To avoid contamination from measurements obtained outside the magnetopause, only measurements at least $2 R_{E}$ earthward (along the EarthSpacecraft line) of the Shue et al. (1997) model magnetopause are retained.

\subsection{Convection velocity maps}

Figure 5 shows the output of this procedure, separately for the Northern and Southern Hemispheres, based on the full data set, i.e., without IMF direction sorting. The two maps at the top show the convection velocities above $58^{\circ}$ latitude in (non-rotating) solar-magnetic (SM) coordinates. The twocell pattern is evident, and so is the effect of co-rotation at low latitudes, enhancing the convection on the dawn side, but reducing it on the dusk side. The velocity vectors are color coded with the number of samples per bin, demonstrating the excellent coverage of both hemispheres, particularly at high latitudes. A minimum of three samples per bin was required for these maps.

The figure also shows the coverage during Northern Hemisphere summer and winter. Due to the Cluster orbit precession, the coverage at latitudes below about $74^{\circ}$ is correlated with season, which might affect the statistics at low latitudes. By the same token our data set is not suited for the study of seasonal effects, except near the central polar cap.

By sorting the Northern Hemisphere velocity data according to the IMF clock-angle, one obtains the maps shown in Fig. 6. The color of the vectors indicates the number of mapped EDI vectors used to calculate the average. While the full dataset shown in the top left of Fig. 5 has now been divided into 8 subsets, the coverage is still quite good: above $74^{\circ}$ latitude, almost all grid points are filled and some of the grid points contain several hundred individual mapped EDI vectors. At lower latitudes, the coverage is sparser, and some of the grid points have less than three measurements or none at all. Since on average the IMF is oriented along the Parker spiral in the GSE- $X Y$ plane, the coverage is highest for IMF sectors 2 and 6, corresponding to $B_{y}+$ and $B_{y}-$, respectively, and lowest for sectors 0 (pure northward IMF, $B_{z}+$ ) and 4 (pure southward IMF, $B_{z}-$ ), as was already evident from the lower panel of Fig. 1.

Figure 6 shows some of the well-known patterns, in particular the anti-sunward convection across the central polar cap, return flows at lower latitudes, and the skewing of the convection caused by IMF $B_{y}$ (sectors 2 and 6), but other features are difficult to discern from this format.

\subsection{Electric potentials}

The most useful representation of the global convection results is in terms of the electric potential distribution, $\Phi$. The potential is related to the convection through the relation:

$\mathbf{E}=-\mathbf{V} \times \mathbf{B}=-\nabla \Phi$

In this paper, we have applied a technique similar to that used for mapping the SuperDARN HF radar observations into global convection maps as described in Ruohoniemi and Baker (1998), which was later refined in a paper by Shepherd and Ruohoniemi (2000). In contrast to the SuperDARN scheme with their one dimensional line-of-sight measurements at the majority of the grid points, the mapped EDI drift velocities are available as full vectors. Only grid points containing more than three mapped EDI drift vectors are considered.

The mapped and averaged drift vector pattern is fitted to an electric potential, $\Phi$, by minimizing the quantity $\chi^{2}$ given by

$\chi^{2}=\sum_{i=1}^{N}\left|\mathbf{E}_{i}+\nabla \Phi\right|^{2}$

where the electric field vector $\mathbf{E}_{i}$, obtained as averages of the cross products between the mapped convection vectors 

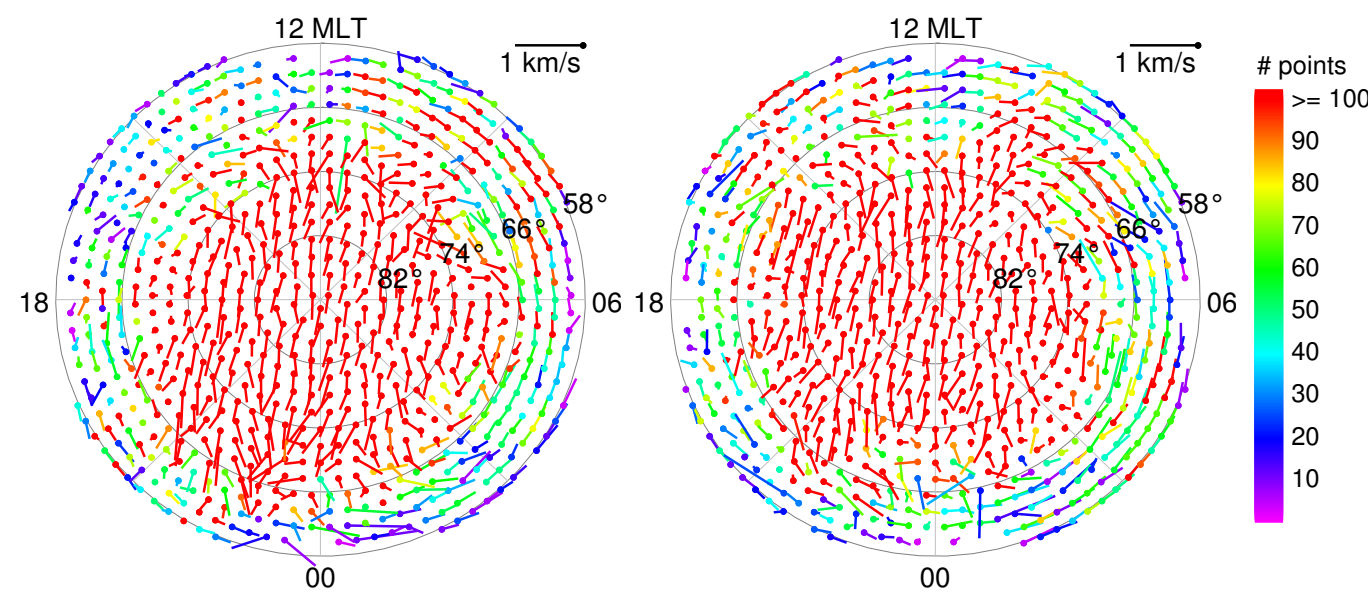

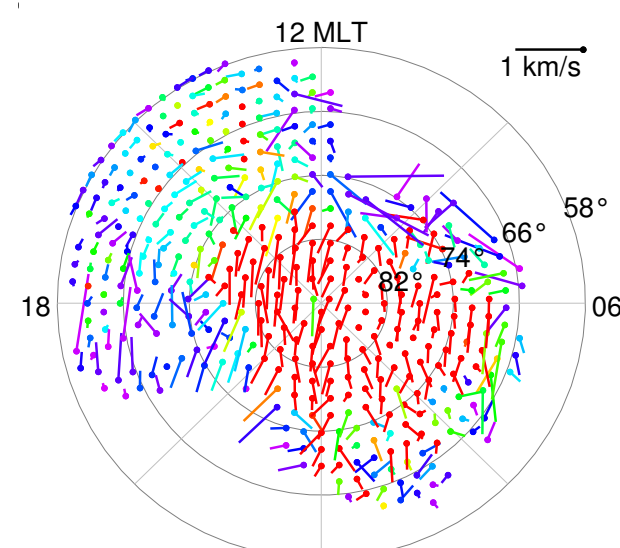

00

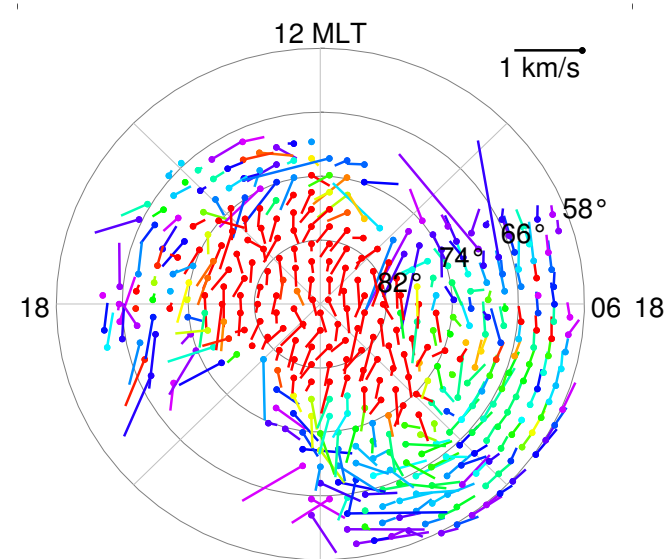

00

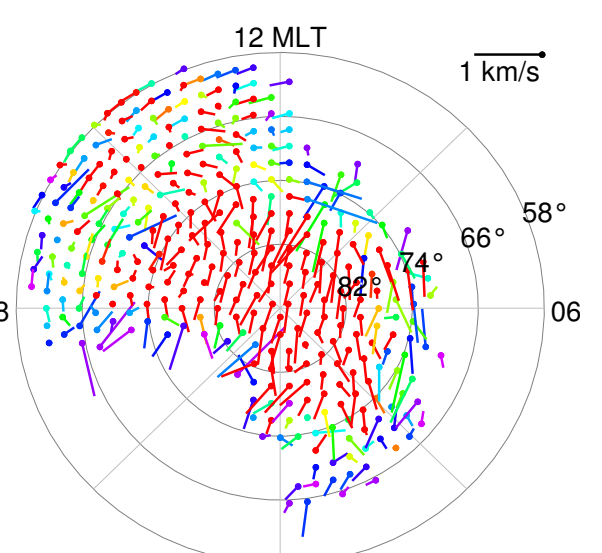

00

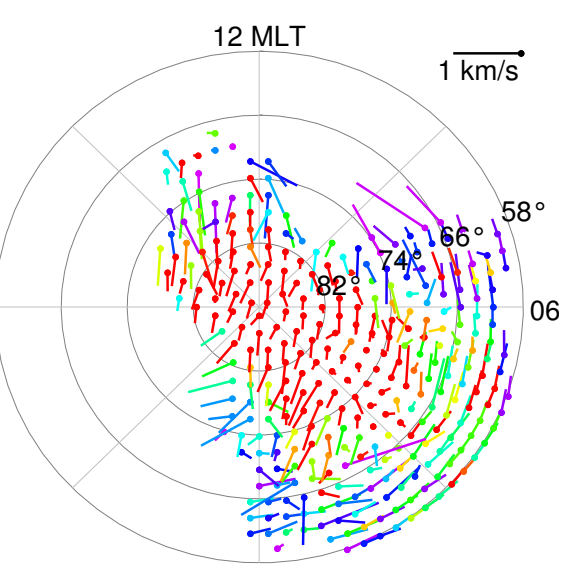

00

Fig. 5. Top: EDI convection velocities, measured from February 2001 through March 2006, mapped into the ionosphere at latitudes above $58^{\circ}$ in SM coordinates for the Northern (left) and Southern (right) Hemispheres. The vectors emanating from the bin centers show the convection velocities, scaled as shown by the arrow in the upper right part. The color of the vectors indicates the number of mapped EDI vectors used to form the average in each bin. Middle: convection velocities and coverage for Northern Hemisphere summer (June to August). Bottom: same for Northern Hemisphere winter (December-February).

and the local ionospheric magnetic field (see Eq. 1), is taken at each grid point containing at least three individual EDI vectors. Basically, one expands the potential as a function of magnetic co-latitude and magnetic local time MLT (here 

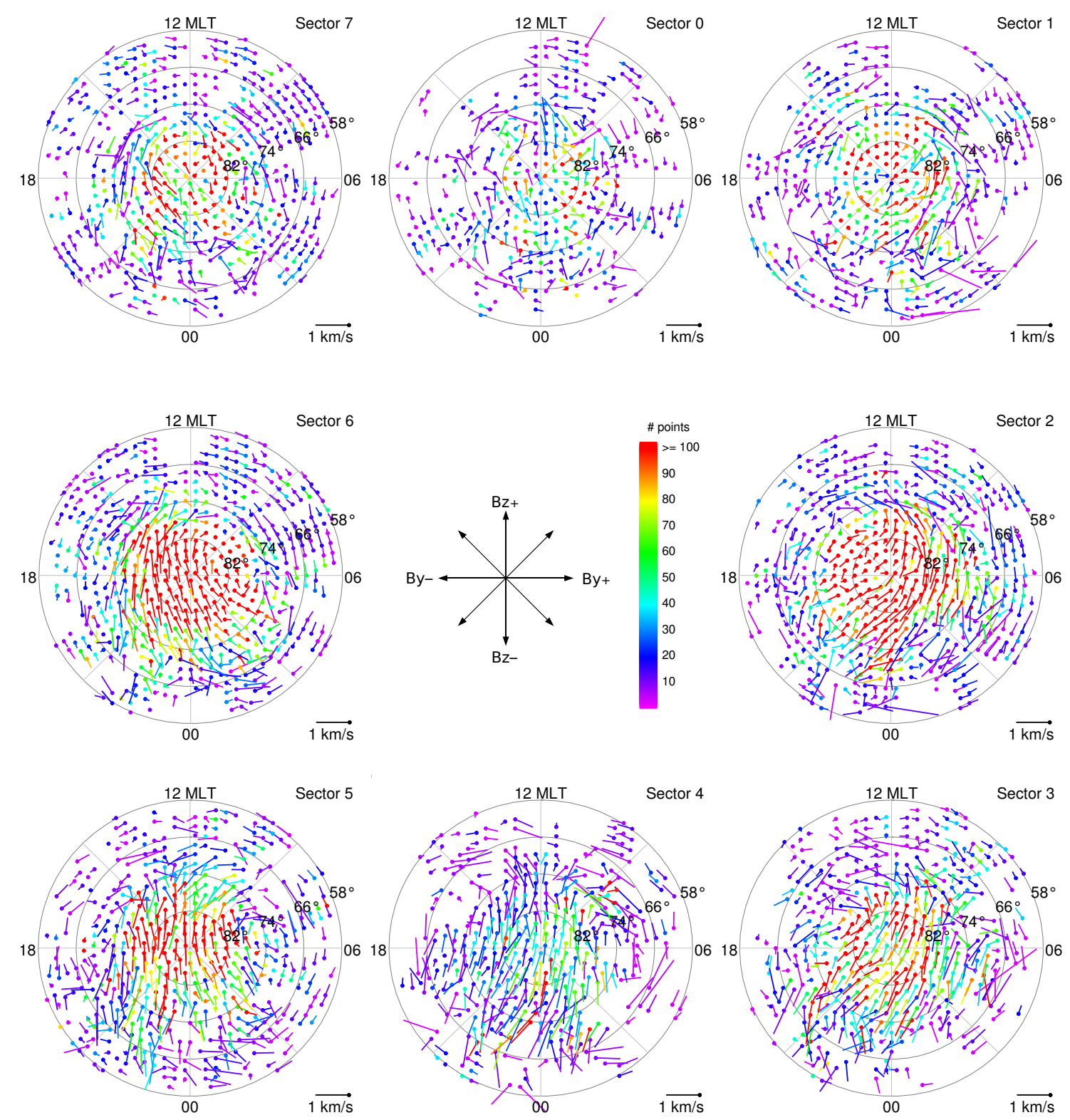

Fig. 6. Convection velocities for the Northern Hemisphere for each of the 8 IMF sectors, mapped into a 784 bin equal-area grid in SM coordinates in the ionosphere. The solid circles mark those grid points where at least three mapped EDI vectors were available for averaging. The number of samples per bin is indicated by the color code. The thin lines emanating from the grid points indicate the convection velocities. Latitude circles are shown at $58^{\circ}, 66^{\circ}, 74^{\circ}$, and $82^{\circ}$.

represented by the azimuthal angle $\phi$ ) in terms of spherical harmonic functions:

$$
\begin{aligned}
\Phi(\theta, \phi) & =\sum_{l=0}^{L} A_{l 0} P_{l}^{0}(\cos \theta) \\
& +\sum_{l=0}^{L} \sum_{m=0}^{l}\left(A_{l m} \cos m \phi+B_{l m} \sin m \phi\right) P_{l}^{m}(\cos \theta)
\end{aligned}
$$

where $P_{l m}$ are the associated Legendre polynomials and $A_{l m}, B_{l m}$ are the real-valued coefficients determined by the eigenvalues (singular values) of the $N \times K$ matrix, with $\mathrm{N}$ being the number of grid points, and $\mathrm{K}$ the number of coefficients. The spatial resolution is determined by the order $\mathrm{L}$ and the degree (running index $m$ ) of the associated Legendre polynomials. In case of equal order and degree of the expansion, like in our study, the number of coefficients is $K=(L+1)^{2}$. In accordance with Ruohoniemi and Greenwald (2005), we used $L=8$ throughout this paper. Prior to the expansion, the magnetic latitude $\lambda_{i}$ of each grid point is transformed into an effective co-latitude $\theta_{i}$ as: 
$\theta_{i}=\frac{\pi / 2-\left|\lambda_{i}\right|}{\pi / 2-\Lambda_{0}} \cdot \pi$

where $\Lambda_{0}$ is the magnetic latitude of the equatorward boundary of our circular grid at $58^{\circ}$. The effective colatitude extends over the whole sphere and guaranties an optimal spatial resolution as well as a stable solution.

An absolute potential is obtained by defining a zero-level at the equatorward boundary, $\Lambda_{0}$, of the convection zone. In this study, we have adapted a modified boundary - the Heppner-Maynard Boundary (HMB) - originally proposed by Heppner and Maynard (1987), which takes into account that the convection boundary is typically located at higher latitudes on the dayside. Following Ruohoniemi and Greenwald (2005), we use different boundaries for the different IMF sectors whose latitudes at local midnight are listed in Table 2. Drift vectors at grid points equatorward of the HMB are padded with zero velocities, which has no significant effect as the velocities at these subauroral latitudes are very small anyway.

\section{Potential distributions}

Figures 7 and 8 show the derived potential maps for the Northern and Southern Hemisphere, respectively, as a function of the interplanetary magnetic field orientation. For ease of comparison with groundbased studies, we have used the co-rotating AACGM coordinate system in these figures. The Southern Hemisphere maps are almost identical with the Northern Hemisphere maps, once one switches the sign of $B_{y}$. We therefore discuss the two together.

For strongly southward IMF (Sector 4) there is the familiar two-cell convection pattern, with strong anti-sunward convection over the poles. In the Northern Hemisphere, the addition of a positive IMF $B_{y}$ component (Sector 3 ) skews the convection cells so that a duskward component appears. This is the effect, noted in Sect. 1, introduced by the asymmetrical addition of open flux to the tail lobes caused by dayside reconnection in the presence of an IMF $B_{y}$. In this framework, one would expect the opposite effect in the case of a negative IMF $B_{y}$ (Sector 5), i.e., a dawnward flow component. But this is not what is observed. Instead the flow is more nearly anti-sunward over the central polar cap. However, the line joining the cell-centers in Sector 5 does have a slope that has the opposite sign of that in Sector 3, although not the same magnitude. For the Southern Hemisphere (Fig. 8) the story is the same, once the sign of $B_{y}$ is reversed and Sectors 3 and 5 exchanged.

When the IMF is essentially in the positive or negative $y$ direction (Sectors 2 and 6, respectively), the appearance of one crescent-shaped and one rounded cell is evident. For the Northern Hemisphere, the skewing of the cells is again stronger for positive IMF $B_{y}$, for the Southern Hemisphere the same is true for negative $B_{y}$.
Table 2. Reference latitude of the Heppner-Maynard boundary (HMB) for each of the 8 IMF sectors. The HMB is characterized here by its magnetic latitude $\Lambda_{0}^{\mathrm{HMB}}$ at midnight. The different HMB extensions are congruent in shape; they are circular on the nightside but withdraw to higher latitudes on the dayside.

\begin{tabular}{clr}
\hline Sector & IMF orientation & $\Lambda_{0}^{\mathrm{HMB}}$ \\
\hline 0 & $B_{z}+$ & $65^{\circ}$ \\
1 & $B_{z}+/ B_{y}+$ & $62^{\circ}$ \\
2 & $B_{y}+$ & $58^{\circ}$ \\
3 & $B_{z}-/ B_{y}+$ & $56^{\circ}$ \\
4 & $B_{z}-$ & $54^{\circ}$ \\
5 & $B_{z}-/ B_{y}-$ & $56^{\circ}$ \\
6 & $B_{y}-$ & $58^{\circ}$ \\
7 & $B_{z}+/ B_{y}-$ & $62^{\circ}$ \\
\hline
\end{tabular}

This lack of mirror symmetry in the potential patterns for positive and negative IMF $B_{y}$ had already been noticed in early electric field observations (Heppner, 1972). Atkinson and Hutchison (1978) showed that the day-night conductivity decrease across the terminator in the E-region ionosphere could result in a deflection of the anti-sunward flow on the nightside of the polar cap towards dusk. This flow deflection should then be visible also in the case of strongly southward IMF, and in fact Figs. 7 and 8 indeed show such a deflection in Sector 4. The idea that it is the non-uniformity of the ionospheric conductivity that causes the breaking of the mirrorsymmetry has been confirmed by Tanaka (2001), based on a numerical MHD simulation that includes the ionosphere in a self-consistent way.

The features just discussed are clearly evident also in previous statistical studies (Rich and Hairston, 1994; Weimer, 1995; Ruohoniemi and Greenwald, 1996; Papitashvili and Rich, 2002; Weimer, 2005; Ruohoniemi and Greenwald, 2005), in particular the slight skewing for strongly southward IMF, and the lack of mirror-symmetry for positive and negative $B_{y}$, which was also very prominent in the empirical model by Heppner and Maynard (1987). All these studies also show a trend, first noticed by Ruohoniemi and Greenwald (2005), that is quite clear in Figs. 7 and 8, namely a counter-clockwise rotation of the line joining the cellcenters, as the IMF rotates from Sector 1 through Sector 7.

For northward IMF (Sector 0 ), the large scale average convection is weak, as evidenced by the much larger spacing of the contours. On the nightside, anti-sunward convection still prevails. But on the dayside, two more cells appear at high magnetic latitudes (centered at $\sim 83^{\circ}$ ), with sunward flow between them. Closer examination reveals that this feature is most prominent for clock angles very close to $0^{\circ}$, i.e., little or no IMF By component. From higher resolution plots (not shown), the potential difference between the two cells is $\sim 14 \mathrm{kV}$ and $\sim 12 \mathrm{kV}$ in the Northern and Southern Hemispheres, respectively. The creation of two counter-rotating 

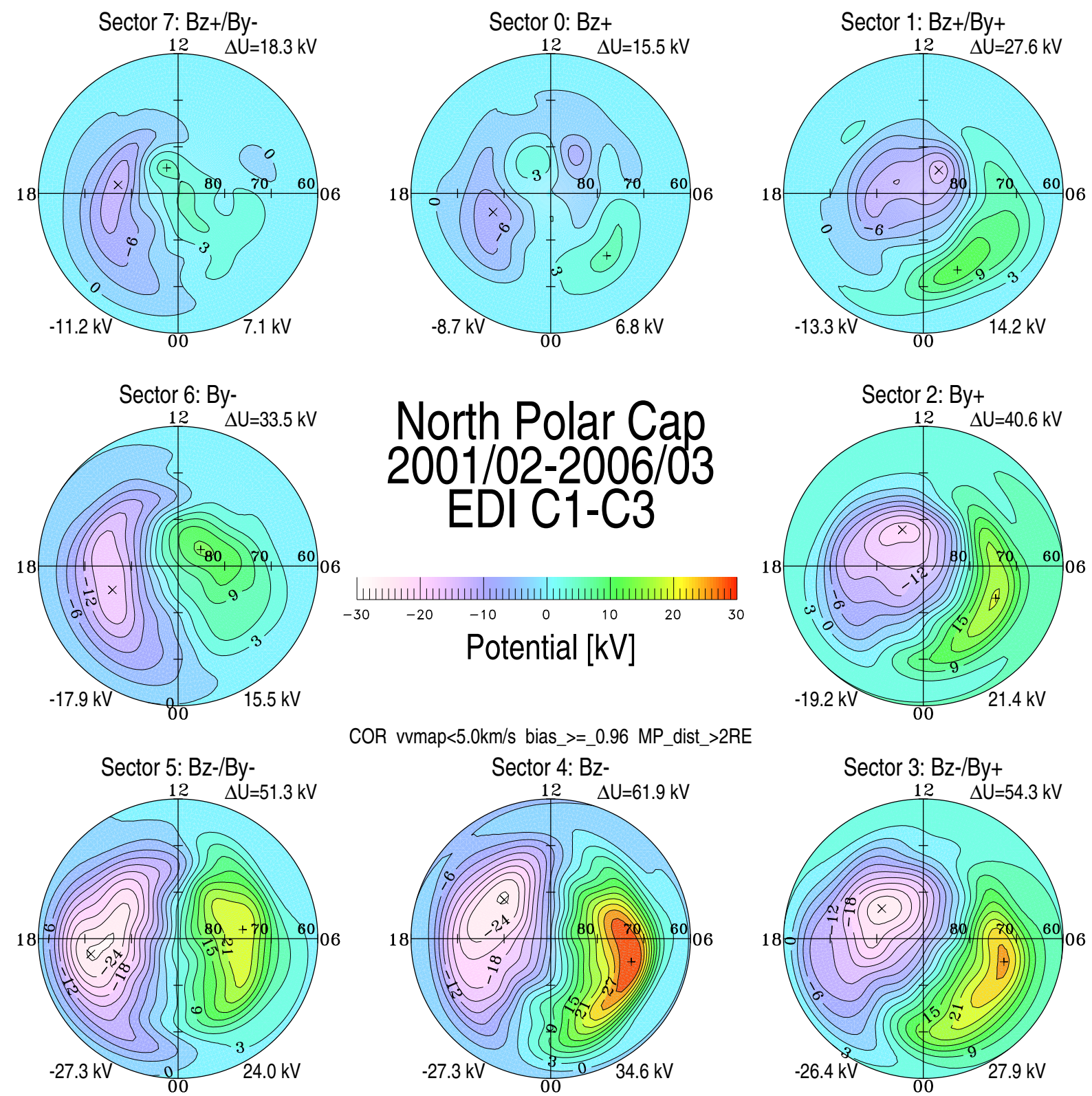

COR vvmap $<5.0 \mathrm{~km} / \mathrm{s}$ bias_>=_0.96 MP_dist_ $>2 \mathrm{RE}$
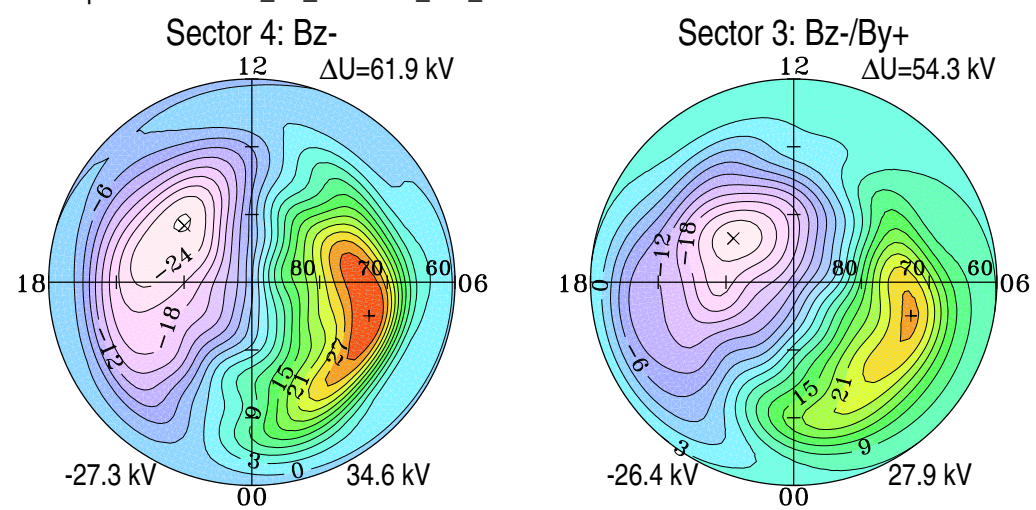

Fig. 7. Electric potentials in the Northern Hemisphere, as a function of AACGM latitude and magnetic local time, for 8 clock-angle orientations of the IMF, obtained by mapping the Cluster EDI velocity measurements into the ionosphere. The background color shows the value of the potential, according to the color bar at the center. Lines are drawn at fixed values of the potential, with a $3 \mathrm{kV}$ spacing.The minimum and maximum potentials are listed at the bottom, and the total potential at the upper right of each map.

convection cells (often referred to as "lobe-cells") through reconnection of already open polar cap field lines with a strongly northward IMF, resulting in a channel of sunward flow in between them, has been predicted by Burke et al. (1979) and Reiff and Burch (1985), and discussed in Cowley and Lockwood (1992); Hill (1994); Reiff and Heelis (1994); Greenwald et al. (1995b). But as far as we know, the resulting four-cell pattern has never been observed this clearly in statistical convection maps. Figure 2 of Weimer (2005) shows a third cell quite clearly for northward IMF, and a fourth cell ever so weakly. Some sunward flow also begins to appear in the maps of Ruohoniemi and Greenwald (2005) for northward IMF, but not in the form of one or two well-defined cells.

For northward IMF combined with a positive or negative $B_{y}$ component (Sectors 1 and 7, respectively), the prediction is for just one extra cell wholly on open field lines (e.g., Reiff and Burch, 1985), but this is not apparent in our data. 

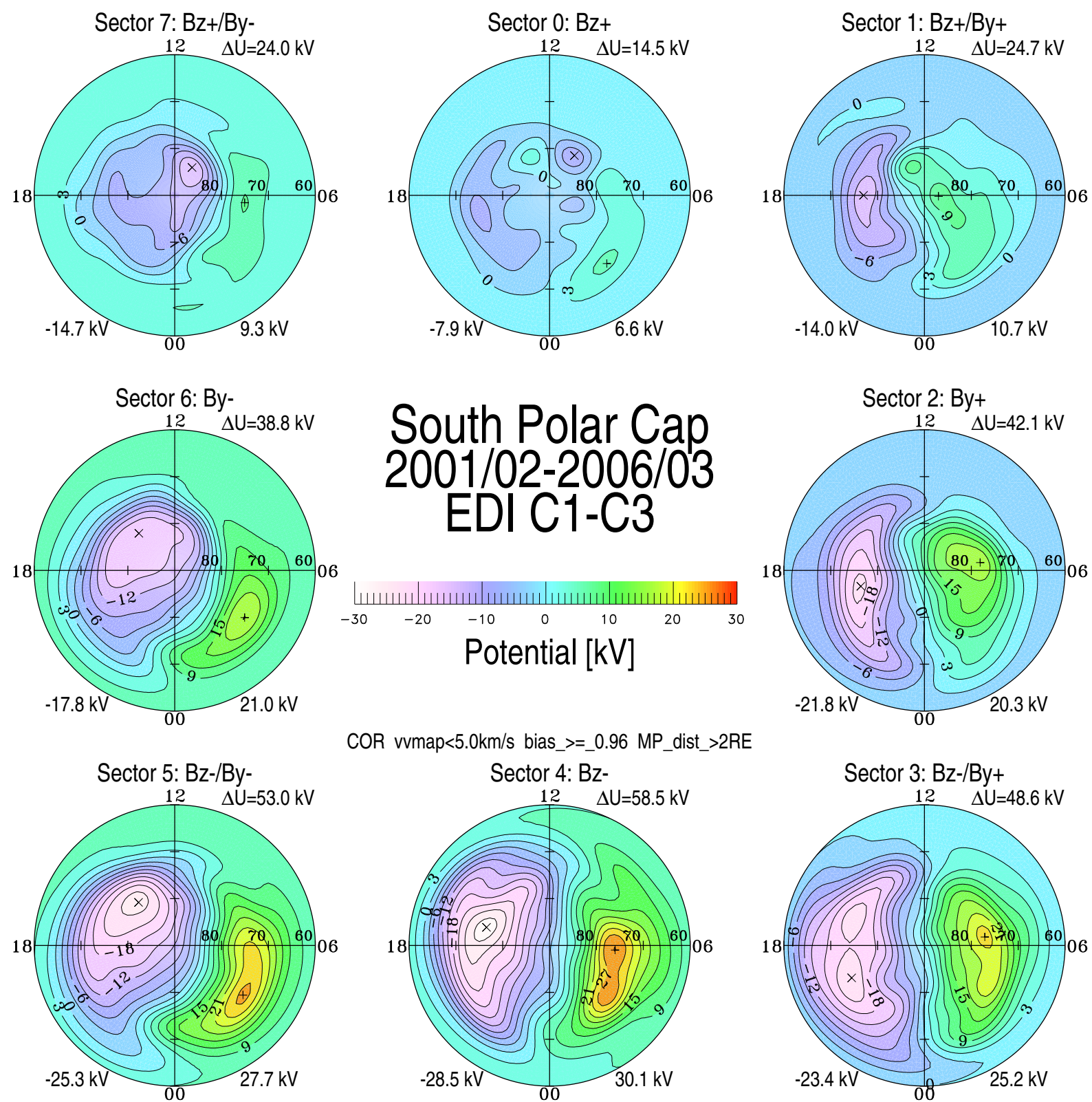

COR vvmap $<5.0 \mathrm{~km} / \mathrm{s}$ bias_ $>=0.96$ MP_dist_ $>2 R E$
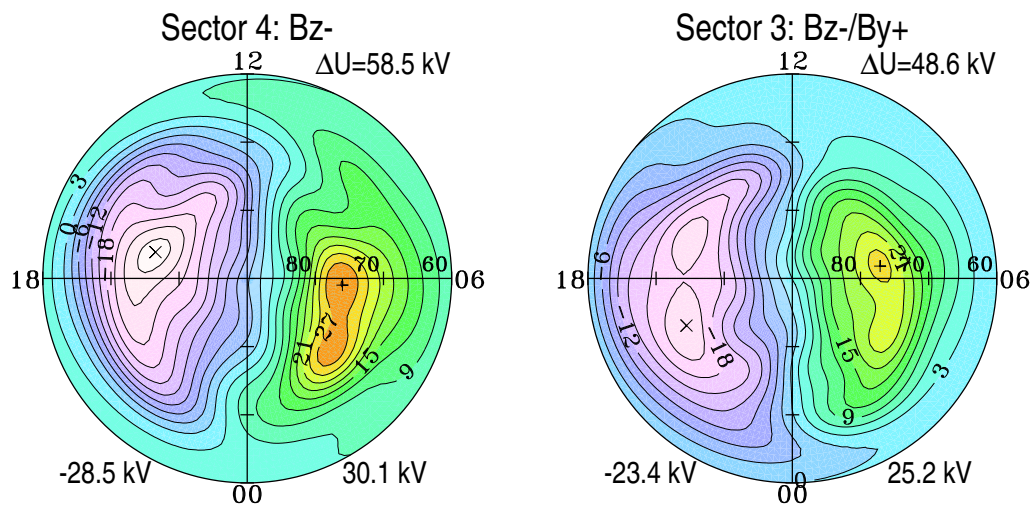

Fig. 8. Same as Fig. 7, but for the Southern Hemisphere.

A quantitative measure of the convection is the total cross polar cap potential drop as a function of the IMF clock-angle. The derivation of these numbers is straightforward for situations with only a single maximum and minimum, but less so if there are more than one each. In those cases (such as Sector 0 in the figures) we have just subtracted the smallest minimum from the largest maximum, which both can be read-off from Figs. 7 and 8 . In Table 3 we list our values for both hemispheres, and those from Papitashvili and Rich (2002), Ruohoniemi and Greenwald (2005), and Weimer (2005) for the Northern Hemisphere only. As Papitashvili and Rich (2002) separate their results according to season, we show the average. Similarly, we also show the average for Ruohoniemi and Greenwald (2005), who separate their results according to the magnitude of the IMF. The results from Weimer (2005) are for a fixed solar wind velocity of $450 \mathrm{~km} \mathrm{~s}^{-1}$ and a solar wind density of $4.0 \mathrm{~cm}^{-3}$, both slightly higher than the corresponding median values of our solar wind data set. Figure 9 shows a plot of the potentials for the Northern Hemisphere listed in Table 3.

Comparison of our numbers for the Northern and Southern Hemisphere shows excellent agreement. Our numbers are somewhat larger than those from Ruohoniemi and Greenwald (2005), but smaller than those of Papitashvili and 
Table 3. Polar cap potentials compared with SuperDARN radar observations (Ruohoniemi and Greenwald, 2005) and a semiempirical model based on measurements from the Dynamics Explorer 2 spacecraft (Weimer, 2005).

\begin{tabular}{llrrrrr}
\hline & \multicolumn{5}{c}{ IMF } & \multicolumn{5}{c}{ Polar cap potentials [kV] } \\
Sector direction & \multicolumn{2}{c}{ This work } & & \\
& & NG05 & PR02 $^{3}$ & W05 $^{4}$ \\
& & S & & & \\
\hline 0 & $B_{z}+$ & 16 & 14 & 15 & 22 & 24 \\
1 & $B_{z}+/ B_{y}+$ & 28 & 25 & 24 & 24 & 40 \\
2 & $B_{y}+$ & 40 & 43 & 36 & 44 & 69 \\
3 & $B_{z}-/ B_{y}+$ & 54 & 50 & 47 & 72 & 93 \\
4 & $B_{z}-$ & 61 & 58 & 48 & 82 & 102 \\
5 & $B_{z}-/ B_{y}-$ & 51 & 55 & 44 & 67 & 90 \\
6 & $B_{y}-$ & 33 & 39 & 35 & 32 & 58 \\
7 & $B_{z}+/ B_{y}-$ & 18 & 25 & 20 & 24 & 32 \\
\hline
\end{tabular}

${ }^{1} N=$ Northern Hemisphere (see Fig. 7), $S=$ Southern Hemisphere (see Fig. 8).

2 averages of numbers in Figs. 5, 6, and 7 in Ruohoniemi and Greenwald (2005).

3 averages of numbers in Figs. 2, 3, and 4 in Papitashvili and Rich (2002).

4 from Fig. 2 in Weimer (2005)

Rich (2002) and especially those from Weimer (2005). For strongly southward IMF, the spread is between $48 \mathrm{kV}$ (Ruohoniemi and Greenwald, 2005), $62 \mathrm{kV}$ (this work), $82 \mathrm{kV}$ (Papitashvili and Rich, 2002) and $102 \mathrm{kV}$ (Weimer, 2005). When considering these differences, one has to remember that they are based on data sets that differ in the underlying measurement techniques, data coverage, the method to derive the potentials distributions, and the epoch the data were taken.

The results of Weimer (2005) are based on double probe measurements from 300-1000 km altitude from the Dynamics Explorer (DE-2) satellite, collected during the period August 1981-March 1983, corresponding to a declining phase of the solar cycle. (As our data were also collected during a declining solar cycle phase, the difference between Weimer (2005) and our results thus cannot be attributed to solar cycle effects). Papitashvili and Rich (2002) used ion drift measurements from $\simeq 840 \mathrm{~km}$ altitude from the Defence Meteorological Satellite Program (DMSP), collected during the period 1987-2001. This dataset thus spans more than a complete eleven-year solar cycle. The SuperDARN results of Ruohoniemi and Greenwald (2005), are based on measurements from 1998-2002.

The various studies also differ significantly in the timeresolution of the IMF data that is used, in the way the IMF propagation delay is being determined, and what criterion, if any, for IMF stability was applied. As a result one can expect different degrees of smearing of the patterns in space, which will directly affect the absolute magnitudes. It is also important to remember that the high-latitude convection is not completely determined by dayside coupling, as expressed by the concurrent direction of the IMF, but also by processes

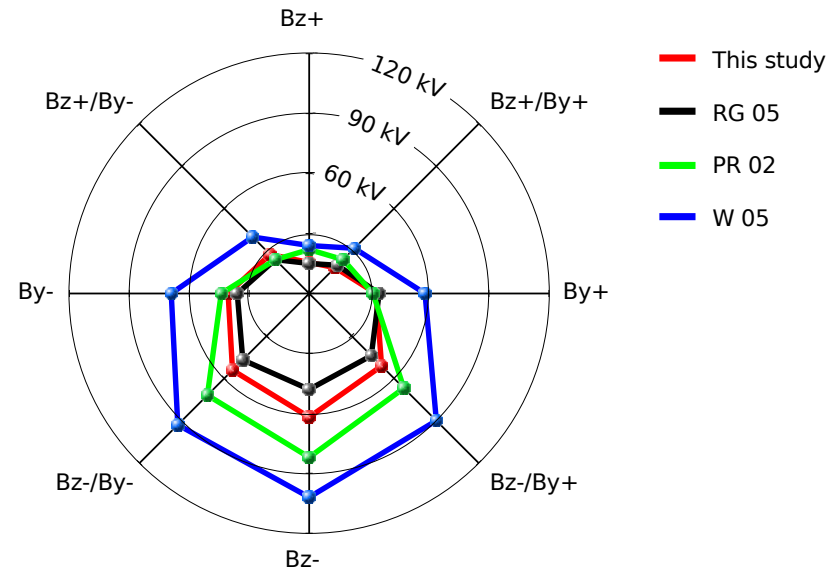

Fig. 9. Illustration of the Northern Hemisphere polar cap potentials as function of IMF direction from various studies. The values of the present study (red curve) fall in-between or overlap those obtained by Ruohoniemi and Greenwald (2005, black curve) and Papitashvili and Rich (2002, green curve), but are consistently lower than the values of Weimer (2005, blue curve). The clock-angle dependency, with the highest potentials for southward IMF, is clearly apparent from all these studies.

in the magnetotail which are not related one-to-one with the concurrent IMF (e.g., Cowley and Lockwood, 1992). A good example for such temporal effects not directly related to the IMF, are the brief dropouts in in the convection velocity reported by Vaith et al. (2004) that appear to be associated with intervals of large substorm activity. Thus the various statistical surveys might have been affected by different numbers of events in the magnetotail that can appear randomly in any one clock-angle sector.

Another feature one notices when comparing the numbers in Table 3 is the tendency, in all four Northern Hemisphere columns, for the Northern Hemisphere potentials to be larger for positive $B_{y}$, i.e., the potential drops in Sector 1 exceeding that in Sector 7, the same for Sector 2 vs. Sector 6, and Sector 3 vs. Sector 5, which to our knowledge has not been discussed before. This looks like another illustration of the lack of mirror-symmetry for positive and negative IMF $B_{y}$. For the Southern Hemisphere the opposite relationship would be expected, with the negative $B_{y}$ sectors having larger potential drops. Our number for the Southern Hemisphere, however, do not confirm this trend. We presently have no explanation for this difference between Northern and Southern Hemisphere.

The observed good agreement between the mapped EDI data and the ground-based or low-altitude measurements, lends credence to the validity of the assumption underlying the mapping, namely that the field lines are equipotentials, at least most of the time. As shown by Baker et al. (2004) for a single event interval, the degree of consistency between EDI and SuperDARN measurements can, however, be quite variable. 
The mapping does, of course, work both ways if field lines are equipotentials. Magnetospheric convection measured at Cluster is therefore not solely the result of the interaction with the solar wind or processes in the magnetotail, but can be modified by the ionosphere. The deflection of flow caused by the non-uniform ionospheric conductivity that was discussed above is a good example of such an effect.

\section{Summary}

We have analyzed approximately $5900 \mathrm{~h}$ of high latitude convection velocity measurements from the Cluster Electron Drift Instrument (EDI), obtained between February 2001 and March 2006, to derive statistical maps of high-latitude convection. The EDI measurements, obtained at geocentric distances between 4 and $20 R_{E}$, are mapped into 784 equalarea bins covering the high latitude $\left(\geq 58^{\circ}\right)$ ionosphere, and sorted according to the direction of the interplanetary magnetic field, as measured on ACE. Separate maps were obtained for the Northern and Southern Hemispheres. When propagating the ACE measurements to the near-Earth region, special care has been taken to include the orientation of the "phase fronts" of the field in the calculation of the delay times. Periods with variable or uncertain solar wind conditions have been excluded from the statistics. The mapping to the ionosphere is based on the Tsyganenko T2001 model.

For southerly IMF, we observe the classic two cell convection pattern with antisunward convection across the polar cap and return flows at lower latitudes. The addition of a positive (negative) IMF $B_{y}$ component causes a clockwise (counterclockwise) rotation of the convection pattern for the Northern Hemisphere, and opposite for the Southern Hemisphere. When IMF $B_{y}$ is dominating, the appearance of one crescent-shaped and one rounded convection cell is evident.

For northward IMF, i.e., little or no IMF $B_{y}$ component, we observe two high-latitude convection cells on the dayside in addition to the large scale global convection cells, thus forming a four-cell pattern. The creation of these additional cells is believed to be a result of reconnection between the strongly northward IMF and the Earth's lobe field at high latitudes. The four cell pattern is apparent both in the Northern and Southern Hemisphere.

The resulting polar cap potential patterns show good agreement with recent statistical results based on SuperDARN radar measurement, model results based on DE-2 low-altitude satellite measurements, and with potential patterns derived from DMSP ion drift measurements. However, the total polar cap potential drops differ between the various studies. When comparing the potential magnitudes, the statistical studies just referred to, do show differences that are probably due to the differences in underlying measurement techniques, data coverage, or methodology.

The good agreement between the mapped EDI measurements and those based on ground-based or low-altitude satel- lite measurements supports the assumption that the magnetic field lines are equipotentials. The fact that the mirrorsymmetry breaking associated with the IMF $B_{y}$ component has been attributed to non-uniformities in ionospheric conductivity (Atkinson and Hutchison, 1978; Tanaka, 2001) is an illustration that magnetospheric convection is not simply the result of processes at the magnetospheric boundaries or the magnetotail, but that it is modified by ionospheric effects.

A final note concerns the fundamental limitation of statistical convection studies. As pointed out by Rich and Hairston (1994), a statistical analysis will necessarily lead to a spreading of any features that are rapidly changing in magnitude or location. Thus the resulting maps cannot be expected to describe in detail the convection pattern that occurs at any one time. In addition there is the effect on the polar cap convection of magnetotail processes that are not always directly related to the concurrent IMF and thus can appear randomly in the maps of any one IMF clock-angle sector.

Acknowledgements. Work at the Max-Planck- Institut für extraterrestrische Physik was supported by Deutsches Zentrum für Luft- und Raumfahrt (DLR). Work at GeoForschungsZentrum (GFZ) Potsdam was supported by Deutsche Forschungsgemeinschaft (DFG). Research at the University of Bergen was supported by the Norwegian Research Council. Work by U.S. investigators was supported in part by NASA grant NNG04GA46G. Parts of the data analysis were done with the QSAS science analysis system provided by the UK Cluster Science Centre (Imperial College London and Queen Mary, University of London) supported by PPARC UK. We thank the ACE SWEPAM and MAG instrument teams and the ACE Science Center for providing the ACE data, and the World Data Center for Geomagnetism, Kyoto, for providing the $D_{s t}$ and ASYM indices. We thank M. Chutter for his support of EDI data analysis and processing, and G. Leistner for providing the averaged EDI data.

Topical Editor I. A. Daglis thanks two referees for their help in evaluating this paper.

\section{References}

Atkinson, G. and Hutchison, D.: Effect of the day night ionospheric conductivity gradient on polar cap convective flow, J. Geophys. Res., 83, 725-729, 1978.

Axford, W. I. and Hines, C. O.: A unifying theory of high-latitude geophysical phenomena and geomagnetic storms, Can. J. Phys., 39, 1433-1464, 1961.

Baker, J. B. H., Greenwald, R. A., Ruohoniemi, J. M., Förster, M., Paschmann, G., Donovan, E. F., Tsyganenko, N. A., Quinn, J. M., and Balogh, A.: Conjugate comparison of Super Dual Auroral Radar Network and Cluster electron drift instrument measurements of the $E \times B$ drift velocities, J. Geophys. Res., 109, 1209, doi:10.1029/2003JA009912, 2004.

Burke, W. J., Kelley, M. C., Sagalyn, R. C., Smiddy, M., and Lai, S. T.: Polar cap electric field structures with a northward interplanetary magnetic field, J. Geophys. Res., 6, 21-24, 1979.

Cowley, S. W. H.: The causes of convection in the earth's magnetosphere - A review of developments during the IMS, Rev. Geophys. Space Phys., 20, 531-565, 1982. 
Cowley, S. W. H. and Lockwood, M.: Excitation and decay of solar wind-driven flows in the magnetosphere-ionosphere system, Ann. Geophys., 10, 103-115, 1992, http://www.ann-geophys.net/10/103/1992/.

Dungey, J. R.: Interplanetary magnetic field and the auroral zones, Phys. Rev. Lett, 6, 47, 1961.

Dungey, J. W.: The structure of the exosphere, or adventures in velocity space, in: Geophysics: The Earth's Environment, edited by: DeWitt, C., Hieblot, J., and Lebeau, A., pp. 503-550, Gordon and Breach, Newark, N.J., 1963.

Eriksson, A. I., André, M., Klecker, B., Laakso, H., Lindqvist, P.-A., Mozer, F., Paschmann, G., Pedersen, A., Quinn, J., Torbert, R., Torkar, K., and Vaith, H.: Electric field measurements on Cluster: comparing the double-probe and electron drift techniques, Ann. Geophys., 24, 275-289, 2006, http://www.ann-geophys.net/24/275/2006/.

Escoubet, C. P., Schmidt, R., and Goldstein, M. L.: Cluster - Science and Mission Overview, Space Sci. Rev., 79, 11-32, 1997.

Förster, M., Haaland, S., Paschmann, G., Baker, J. B., Vaith, H., Quinn, J. M., and Torbert, R. B.: Cross-Polar Magnetospheric Plasma Drift as Observed by Cluster EDI: Statistical results, in: Proceedings of the Cluster and Double Star Symposium - 5th Anniversary of Cluster in Space, edited by: Escoubet, C. P., vol. ESA SP-598, ESA Publications Division, ESTEC, Noordwijk, The Netherlands, ISBN 92-9092-909-X, ISSN 1609-042X, 2006.

Gosling, J. T., Thomsen, M. F., Bame, S. J., Elphic, R. C., and Russell, C. T.: Plasma flow reversals at the dayside magnetopause and the origin of asymmetric polar cap convection, J. Geophys. Res., 95, 8073-8084, 1990.

Greenwald, R. A., Baker, K. B., Dudeney, J. R., Pinnock, M., Jones, T. B., Thomas, E. C., Villain, J.-P., Cerisier, J.-C., Senior, C., Hanuise, C., Hunsucker, R. D., Sofko, G., Koehler, J., Nielsen, E., Pellinen, R., Walker, A. D. M., Sato, N., and Yamagishi, H.: DARN/SuperDARN: A Global View of the Dynamics of HighLatitude Convection, Space Sci. Rev., 71, 761-796, 1995a.

Greenwald, R. A., Bristow, W. A., Sofko, G. J., Senior, C., Cerisier, J.-C., and Szabo, A.: Super Dual Auroral Radar Network radar imaging of dayside high-latitude convection under northward interplanetary magnetic field: Toward resolving the distorted twocell versus multicell controversy, J. Geophys. Res., 100, 1966119674, doi:10.1029/95JA01215, 1995 b.

Haaland, S., Paschmann, G., and Sonnerup, B. U. Ö.: Comment on "A new interpretation of Weimer et al.'s solar wind propagation delay technique" by Bargatze et al., J. Geophys. Res. (Space Physics), 111, 6102-6106, doi:10.1029/2005JA011376, 2006.

Heppner, J.: Polar-cap electric field distributions related to the interplanetary magnetic field direction, J. Geophys. Res., 77, 48774887, 1972.

Heppner, J. P. and Maynard, N. C.: Empirical high-latitude electric field models, J. Geophys. Res., 92, 4467-4489, 1987.

Hill, T. W.: Theoretical models of polar-cap convection under the influence of a northward interplanetary magnetic field, J. Atmos. Terr. Phys., 56, 185-194, 1994.

Kamide, Y., Richmond, A. D., and Matsushita, S.: Estimation of ionospheric electric fields, ionospheric currents, and fieldaligned currents from ground magnetic records, J. Geophys. Res., 86, 801-813, 1981.

Lockwood, M. and Moen, J.: Reconfiguration and closure of lobe flux by reconnection during northward IMF: possible evidence for signatures in cusp/cleft auroral emissions, Ann. Geophys., 17, 996-1011, 1999,

http://www.ann-geophys.net/17/996/1999/.

Matsui, H., Jordanova, V. K., Quinn, J. M., Torbert, R. B., and Paschmann, G.: Derivation of electric potential patterns in the inner magnetosphere from Cluster EDI data: Initial results, J. Geophys. Res., 109, 10 202, doi:10.1029/2003JA010319, 2004.

Matsui, H., Quinn, J. M., Torbert, R. B., Jordanova, V. K., PuhlQuinn, P. A., and Paschmann, G.: IMF BY and the seasonal dependences of the electric field in the inner magnetosphere, Ann. Geophys., 23, 2671-2678, 2005, http://www.ann-geophys.net/23/2671/2005/.

McComas, D. J., Bame, S. J., Barker, P., Feldman, W. C., Phillips, J. L., Riley, P., and Griffee, J. W.: Solar Wind Electron Proton Alpha Monitor (SWEPAM) for the Advanced Composition Explorer, Space Sci. Rev., 86, 563-612, 1998.

Noda, H., Baumjohann, W., Nakamura, R., Torkar, K., Paschmann, G., Vaith, H., Puhl-Quinn, P., Förster, M., Torbert, R., and Quinn, J. M.: Tail lobe convection observed by Cluster/EDI, J. Geophys. Res., 108, 1288, doi:10/1029/2002JA009669, 2003.

Papitashvili, V. O. and Rich, F. J.: High-latitude ionospheric convection models derived from Defense Meteorological Satellite Program ion drift observations and parameterized by the interplanetary magnetic field strength and direction, J. Geophys. Res., 107, 1198, doi:10.1029/2001JA000264, 2002.

Paschmann, G., Melzner, F., Frenzel, R., Vaith, H., Parigger, P., Pagel, U., Bauer, O. H., Haerendel, G., Baumjohann, W., Scopke, N., Torbert, R. B., Briggs, B., Chan, J., Lynch, K., Morey, K., Quinn, J. M., Simpson, D., Young, C., McIlwain, C. E., Fillius, W., Kerr, S. S., Mahieu, R., and Whipple, E. C.: The Electron Drift Instrument for Cluster, Space Sci. Rev., 79, 233-269, 1997.

Paschmann, G., Quinn, J. M., Torbert, R. B., Vaith, H., McIlwain, C. E., Haerendel, G., Bauer, O. H., Bauer, T., Baumjohann, W., Fillius, W., Förster, M., Frey, S., Georgescu, E., Kerr, S. S., Kletzing, C. A., Matsui, H., Puhl-Quinn, P., and Whipple, E. C.: The Electron Drift Instrument on Cluster: overview of first results, Ann. Geophys., 19, 1273-1288, 2001, http://www.ann-geophys.net/19/1273/2001/.

Quinn, J. M., Paschmann, G., Torbert, R. B., Vaith, H., McIlwain, C. E., Haerendel, G., Bauer, O., Bauer, T. M., Baumjohann, W., Fillius, W., Förster, M., Frey, S., Georgescu, E., Kerr, S. S., Kletzing, C. A., Matsui, H., Puhl-Quinn, P., and Whipple, E. C.: Cluster EDI convection measurements across the high-latitude plasma sheet boundary at midnight, Ann. Geophys., 19, 16691681, 2001, http://www.ann-geophys.net/19/1669/2001/.

Reiff, P. H. and Burch, J. L.: IMF B(y)-dependent plasma flow and Birkeland currents in the dayside magnetosphere. II - A global model for northward and southward IMF, J. Geophys. Res., 90, 1595-1609, 1985.

Reiff, P. H. and Heelis, R. A.: Four cells or two? Are four convection cells really necessary?, J. Geophys. Res., 99, 3955-3959, 1994.

Rich, F. J. and Hairston, M.: Large-scale convection patterns observed by DMSP, J. Geophys. Res., 99, 3827-3844, 1994.

Richmond, A. D. and Kamide, Y.: Mapping electrodynamic features of the high-latitude ionosphere from localized observations - Technique, J. Geophys. Res., 93, 5741-5759, 1988. 
Ridley, A., Clauer, C., Lu, G., and Papitashvili, V.: A statistical study of the ionospheric convection response to changing interplanetary magnetic field conditions using the assimilative mappic of ionospheric electrodynamics technique, J. Geophys. Res., 103, 4023-4039, 1998.

Ruohoniemi, J. and Greenwald, R.: Statistical patterns of highlatitude convection obtained from Goose Bay HF radar observations, J. Geophys. Res., 101, 21 743-21 763, 1996.

Ruohoniemi, J. M. and Baker, K. B.: Large-scale imaging of highlatitude convection with Super Dual Auroral Radar Network HF radar observations, J. Geophys. Res., 103, 20 797-20 812, 1998.

Ruohoniemi, J. M. and Greenwald, R. A.: Dependencies of highlatitude plasma convection: Consideration of interplanetary magnetic field, seasonal, and universal time factors in statistical patterns, J. Geophys. Res., 110, 9204, doi:10.1029/2004JA010815, 2005.

Russell, C.: The configuration of the magnetosphere, in: Critical Problems of Magnetospheric Physics, edited by: Dyer, E., p. 1, Nature Academy of Science, Washington, 1972.

Shepherd, S. G. and Ruohoniemi, J. M.: Electrostatic potential patterns in the high-latitude ionosphere constrained by SuperDARN measurements, J. Geophys. Res., 105, 23 005-23 014, doi:10.1029/2000JA000171, 2000.

Shue, J.-H., Chao, J. K., Fu, H. C., Russell, C. T., Song, P., Khurana, K. K., and Singer, H. J.: A new functional form to study the solar wind control of the magnetopause size and shape, J. Geophys. Res., 102, 9497-9512, doi:10.1029/97JA00196, 1997.

Smith, C. W., L'Heureux, J., Ness, N. F., Acuña, M. H., Burlaga, L. F., and Scheifele, J.: The ACE Magnetic Fields Experiment, Space Sci. Rev., 86, 613-632, 1998.

Tanaka, T.: Interplanetary magnetic field $B_{y}$ and auroral conductance effects on high-latitude ionospheric convection patterns, J. Geophys. Res., 106, 24 505-24 516, 2001.
Tsyganenko, N. A.: A model of the near magnetosphere with a dawn-dusk asymmetry 1. Mathematical structure, J. Geophys. Res. (Space Physics), 107, 1179, doi:10.1029/2001JA000219, 2002a.

Tsyganenko, N. A.: A model of the near magnetosphere with a dawn-dusk asymmetry 2. Parameterization and fitting to observations, J. Geophys. Res. (Space Physics), 107, 1176, doi: 10.1029/2001JA000220, 2002b.

Vaith, H., Paschmann, G., Quinn, J., Förster, M., Georgescu, E., Haaland, S., Klecker, B., Kletzing, C., Puhl-Quinn, P., Rème, H., and Torbert, R.: Plasma convection across the polar cap, plasma mantle and cusp: Cluster EDI observations, Ann. Geophys., 22, 2451-2461, 2004, http://www.ann-geophys.net/22/2451/2004/.

Weimer, D.: Models of high-latitude electric potentials derived with a least error fit of spherical harmonic coefficients, J. Geophys. Res., 100, 19595-19607, 1995.

Weimer, D. R.: Improved ionospheric electrodynamic models and application to calculating Joule heating rates, J. Geophys. Res. (Space Physics), 110, 5306, doi:10.1029/2004JA010884, 2005.

Weimer, D. R., Ober, D. M., Maynard, N. C., Burke, W. J., Collier, M. R., McComas, D. J., Ness, N. F., and Smith, C. W.: Variable time delays in the propagation of the interplanetary magnetic field, J. Geophys. Res. (Space Physics), 107, 1210, doi: 10.1029/2001JA009102, 2002.

Weimer, D. R., Ober, D. M., Maynard, N. C., Collier, M. R., McComas, D. J., Ness, N. F., Smith, C. W., and Watermann, J.: Predicting interplanetary magnetic field (IMF) propagation delay times using the minimum variance technique, J. Geophys. Res. (Space Physics), 108, 1026, doi:10.1029/2002JA009405, 2003. 